\title{
Influence of polymer structure and amount on microstructure and properties of polyethylene-modified asphalt binders
}

\author{
K. Lakshmi Roja (i) Amara Rehman - Mabrouk Ouederni - Senthil Kumar Krishnamoorthy • \\ Ahmed Abdala $\cdot$ Eyad Masad
}

Received: 4 December 2020/ Accepted: 9 March 2021 / Published online: 8 April 2021

(C) The Author(s) 2021

\begin{abstract}
In recent years, the use of polyethylene (PE) for asphalt modification has been gaining increased attention due to the environmental sustainability and cost-saving benefits. To optimize the performance of the PE-asphalt blends, it is necessary to understand the polymer-binder interactions and their impact on the properties of the modified asphalt binder. In this study, low-density polyethylene (LDPE) with low and high melt flow index (MFI), i.e., LDPE4 and LDPE70, were blended with Pen 60-70 asphalt binder in dosages ranging from 1 to 5 wt.\%. PE Wax was also added to the binder or the PEbinder blend to enhance dispersion. The dispersion of PE in the binder and the phase stability of the modified binder were investigated by optical microscope. The equivalent diameter of PE domains increased with time and the polymer dosage level. The addition of PE wax improved the polymer dispersity in the LDPE4 blends. The polymer dispersity in LDPE70 blends was good without adding PE Wax, attributed to the higher
\end{abstract}

\section{K. L. Roja $(\bowtie) \cdot$ E. Masad}

Mechanical Engineering Program, Texas A\&M

University at Qatar, Doha, Qatar

e-mail: lakshmi.kakumanu@qatar.tamu.edu

A. Rehman · A. Abdala

Chemical Engineering Program, Texas A\&M University at Qatar, Doha, Qatar

M. Ouederni · S. K. Krishnamoorthy

Qatar Petrochemical Company (QAPCO), Doha, Qatar
MFI value (low molecular weight) of LDPE70. In addition, to understand the stability of polymer modified binder, the steady shear viscosity-temperature profile of these binders was studied using a rotational viscometer. The dynamic rheological properties and performance of the PE-binder blends were evaluated using the dynamic shear rheometer. Based on the microstructure, all other rheological and performance properties, it was concluded that the 3\% LDPE70 binder has better polymer dispersity, better low and high temperature performance characteristics.

Keywords Polymer modified asphalt binder . Optical microscopy · Low-density polyethylene . Rheological properties $\cdot$ Viscosity-temperature profile

\section{Introduction}

Asphalt modification using plastics started in the early 1980's [1]. Initial works involved the use of polyethylene (PE) alone without other additives; continuous agitation was required to prevent separation of PE from asphalt until asphalt mixture is laid. Early research studies focused on the characterization of PE modified asphalt mixture and pavement performance evaluation [2-6], while many of the recent studies focused on improving stability of the PEbinder blend [7-10]. When blending PE with asphalt 
binder, it is necessary first to understand the interaction between PE and asphalt binder and how the addition of PE impacts the thermal and rheological behavior of the binder.

Low-Density Polyethylene (LDPE) is the most commonly used PE polymer for asphalt modification [11-14]. The properties of PE modified binders are highly dependent on the mixing conditions $[15,16]$. Polacco et al. [17] reported that long high-shear mixing changes the asphalt binder's molecular weight and chemistry and significantly influences the polymer swelling. Dalhat et al. [16] recommended a mixing temperature of $50^{\circ} \mathrm{C}$ above the PE melting temperature, but not exceeding $190^{\circ} \mathrm{C}$ to avoid binder oxidation at high temperatures. Based on the blend viscosity, dynamic modulus $\left(G^{*}\right)$ values and phase angle $(\delta)$ values, the optimum blending time, blending speed, and LDPE dosage was selected as $30 \mathrm{~min}$, 1300-5000 rpm, and 3-5\%, respectively [16, 18-20].

The properties of polymer-modified binders are influenced by many factors: the type and properties of polymer, polymer size, binder source, and blending conditions. The stability/compatibility of polymer modified binder (PMB) depends on the capability of polymer swelling with maltene molecules and asphaltene content [21]. Some polymers like PE have low miscibility/solubility in binder, resulting in the separation of the two components. Polacco et al. [12] reported that the polymer - binder compatibility is enhanced when the asphalt binder with high aromatic content and low asphaltene content is used [16, 22]. In a study conducted by Liang et al. [23], optical microscopic analysis was carried out on PE modified asphalt binder, and the phase separation of PE and asphalt binder was simulated using phase-field model coupled with the Navier-Stokes equation. They concluded that LDPE disperses better in the binder than HDPE. In another study, Ho et al. [7] combined PE Wax with LDPE/HDPE/recycled PE to improve the binder-PE compatibility. Their results revealed that a very low molecular weight $\left(M_{w}\right)$ PE with wide molecular weight distribution (MWD) and high melt flow index (MFI) has less tendency to separate from asphalt binder [9].

The addition of PE reduces the amount of asphalt binder used and improves the high temperature performance properties of asphalt binder/mix $[3,4,16,19,20]$. The major challenge with $\mathrm{PE}$ modified asphalt is the phase separation/storage stability. When PE is blended with the binder, they tend to separate, because PE is a nonpolar and nonaromatic polymer. This low compatibility between $\mathrm{PE}$ and binder leads to storage stability issues. In addition, the reason for the low compatibility could be the differences in molecular structure, density, molecular weight, and viscosity of the polymer and bitumen components. Hence, by controlling these parameters, the phase separation can be reduced.

This study evaluates the efficacy of using locally produced PE polymer as a modifier for asphalt binders. This aim is achieved by analyzing the dispersion of the polymer domains in the LDPE modified binders and improving the compatibility between the LDPE and binder with the addition of PE wax. Therefore, the study focuses on the following tasks:

- Analyzing the thermal properties of polymerbinder blends.

- Analyzing the dispersion of polymer in the polymer-binder blends and investigating the phase stability after mixing.

- Identifying the instability of PMB from the viscosity-temperature profiles.

- Analyzing the impact of the polymer type and addition level on the steady and dynamic rheological properties of the polymer-binder blends.

- Determining the grade of polymer blended binders based on the high, intermediate and low temperature performance characteristics.

\section{Materials and methods}

\subsection{Materials}

A base binder of pen 60-70 grade was used in this study. Two different LDPE samples and one PE wax sample were supplied by Qatar Petrochemicals Company (QAPCO) and used as a modifier to the asphalt binder. PE wax is a very low molecular weight byproduct of the LDPE polymerization process (molecular weight: 6000). The two LDPE materials have different properties: LDPE4 has low MFI of $4 \mathrm{~g} / 10$ $\mathrm{min}, \mathrm{LDPE} 70$ has high MFI of $70 \mathrm{~g} / 10 \mathrm{~min}$. 


\subsection{Blend processing}

The blends were produced by adding the polymer to asphalt binder at different concentrations ranging from $1-5$ wt. $\%$. The blend is designated as $\mathrm{x} \%$ LDPE $\mathrm{y}$, where $\mathrm{x}$ is the polymer concentration in the blend and $\mathrm{y}$ is the polymer MFI. Blends containing both LDPE and PE wax are designated as $\mathrm{x} \%$ LDPE $\mathrm{y}+\mathrm{z} \%$ wax, where $\mathrm{z}$ is the weight percentage of the PE wax in the blend. The polymer-binder designations are $1 \%$ LDPE4, 2\% LDPE4, 3\% LDPE4, 4\% LDPE4, 5\% LDPE4, 3\% LDPE70, 5\% LDPE70, 3\% PE wax,2\% LDPE4+1\% wax, $4 \%$ LDPE70+1\% wax. The blending procedure was as follows: (1) the binder was preheated at $180^{\circ} \mathrm{C}$ for $1 \mathrm{~h}$, (2) the polymer (LDPE pellets and/or PE wax) were added to the binder and kept the blend in an oven at $180^{\circ} \mathrm{C}$ for $30 \mathrm{~min}$, and (3) the polymer-binder blend was mixed using a shear mixer operating at $2000 \mathrm{rpm}, 180^{\circ} \mathrm{C}$ for $1 \mathrm{~h}$.

\subsection{Thermal properties of polymer and polymer- binder blends}

Thermogravimetric Analyzer (TGA) was used to determine the thermal stability of the PE-asphalt blends. This test was carried out using Perkin Elmer's Pyris 6 instrument by heating $15 \mathrm{mg}$ of the sample from 30 to $550^{\circ} \mathrm{C}$ at a rate of $10^{\circ} \mathrm{C} / \mathrm{min}$ under $N_{2}$. Then, the percentage of mass loss was determined as a function of temperature. The decomposition temperatures corresponding to $5 \%$ mass loss $\left(T_{0.05}\right)$ were 356 , $368,360,375^{\circ} \mathrm{C}$ for Pen $60-70,3 \%$ LDPE4, 3\% PE wax and $2 \%$ LDPE4+1\% PE wax, respectively. LDPE modification enhanced the thermal properties of the blend. The TGA experiment was not carried out on LDPE70 blends because the decomposition temperatures of LDPE4 blends were substantially higher than that of its use temperature. Hence, the Differential Scanning Calorimetry (DSC) tests were carried out to characterize the thermal behavior of the polymermodified blends.

The thermograms of polymers, polymer modified binders were collected using Perkin Elmer's Jade DSC machine. Then, the thermo-mechanical properties (melting point temperature $\left(T_{m}\right)$, and heat of fusion $\left(\Delta H_{f}\right)$ ) were determined as shown in Table 1 . The melting point and heat of fusion of LDPE+binder was lower than that of the corresponding LDPE polymer. The reduction in $\Delta H_{f}$ could be due to the disruption of the crystalline structure caused by the swelling of polymers [24]; thus, smaller crystallites result in the lower melting point of polymer modified binder.

\subsection{Microstructural and rheological characterization of polymer-binder blends}

\subsubsection{Optical microscopy}

The optical microscope images of all the binders were captured by preparing the samples on a microscope glass slide using the heat and cast approach [25, 26]. Then the samples were cooled at room temperature and imaged at 30,60, 90, and 150 min post-blending. The optical images were captured using Zeiss AxiVert 40 MAT fitted with ERc5s camera. The size of each image was $2560 \times 1920$ pixels $(1083 \mu \mathrm{m} \times 809 \mu \mathrm{m})$. To check the uniformity in polymer dispersion, minimum five images were captured for each binder.

\subsubsection{Steady-shear (rotational) rheology}

The steady shear viscosity of the base binder and PE asphalt binders was measured at different temperatures using Brookfield rotational viscometer utilizing SC 4-27 spindle. About 10.5 grams of asphalt binder sample were poured in the rotational viscometer containers. To analyze the stability of PE-blended binders and the state of phase separation, the viscosity hysteresis of the binders was measured during temperature decrement and increment. In this test, PEblended binders were sheared at $20 \mathrm{rpm}$ and the viscosity was measured at $160,145,130,115,100$, $100,115,130,145$ and $160{ }^{\circ} \mathrm{C}$. The binder blends were sheared for $15 \mathrm{~min}$ at each temperature. Out of the total $15 \mathrm{~min}$, the first $5 \mathrm{~min}$ were considered as pre-shearing time and the last $10 \mathrm{~min}$ were the actual testing time as shown in Fig. 1a. The experimental data capture of time, temperature, and viscosity of 3\% LDPE4 binder are presented in Fig. 1b. In this last $10 \mathrm{~min}$, the viscosity at 6 th, 7 th, and 8 th min were averaged and reported.

\subsubsection{Dynamic rheology}

Dynamic rheological experiments were conducted using dynamic shear rheometer (DSR) for the selected polymer blends. The viscoelastic properties of PEbinder blends were determined using the frequency 
Table 1 Melting point and heat of fusion values obtained from DSC data

\begin{tabular}{lll}
\hline Material & Peak melting point $\left({ }^{\circ} \mathrm{C}\right)$ & $\Delta H_{f}(\mathrm{~J} / \mathrm{g})$ \\
\hline Plain binder & & \\
Pen 60-70 & 72.3 & 0.04 \\
Plain polymer & & \\
LDPE4 & 119.3 & 65.3 \\
LDPE70 & 111.8 & 44.8 \\
PE wax & 102.1 & 1.43 \\
LDPE + binder & & \\
5\% LDPE4 & 103.8 & 5.3 \\
5\% LDPE70 & 94.4 & 4 \\
LDPE+PE wax + binder & & 1.8 \\
4\% LDPE4+1\% wax & 100.1 & 4.2 \\
3\% wax & 94.1 & 0.17 \\
\hline
\end{tabular}

sweep test. While the rutting resistance of blends were evaluated using the multiple stress creep and recovery (MSCR) test [27], the fatigue failure cycles were determined using the linear amplitude sweep (LAS) test [28]. Finally, the PE-binder blends were graded based on their high and low-temperature performance characteristics [29]. The repeatability of each test was checked by conducting at least two trials, and the percentage difference between the two trials was less than $5 \%$ from the mean.

\subsubsection{Frequency sweep test In this test, the unaged} PE-binder blends were oscillated at a frequency range of $15-1 \mathrm{~Hz}$ (rate: $1 \mathrm{~Hz} / \mathrm{s}$ ), at different temperatures in the range of $25-65^{\circ} \mathrm{C}$ (increment interval: $10^{\circ} \mathrm{C}$ ). At each temperature, the ratio of peak stress to strain and the time lag between stress-strain curves were used to calculate the dynamic modulus $\left(\left|\mathrm{G}^{*}\right|\right)$ and phase angle $(\delta)$, respectively. The temperature isotherms were shifted individually to a reference temperature and constructed master curves.

\subsubsection{Multiple stress creep and recovery (MSCR)} test [27] To compare the rutting behavior of all short-term aged (RTFO) binders, the MSCR test was carried out at a single temperature of $64^{\circ} \mathrm{C}$. In this test, two stress levels of 0.1 and $3.2 \mathrm{kPa}$ were applied [27]. The binders were subjected to 10 creep loading and recovery cycles at each stress level; the loading time is $1 \mathrm{~s}$ and recovery is $9 \mathrm{~s}$. For each cycle, the non- recoverable creep compliance $\left(J_{n r}\right)$ was measured and their average for each stress level was reported.

\subsubsection{Linear amplitude strain sweep test (LAS)} [28] Using this test, the fatigue response of all long-term (PAV) aged binders was determined at a single temperature of $25^{\circ} \mathrm{C}$. In this test method, first, the frequency sweep was conducted to determine the linear viscoelastic parameters. In continuation, the linear strain amplitude sweep test was conducted to determine the damage parameter. The test parameters were selected as prescribed in AASHTO TP 101 [28]. In LAS test, the strain increased linearly from 0 to $30 \%$ in 31000 cycles $(3100 \mathrm{~s})$. The peak shear stress and strain values were captured at each second.

2.4.3.4 Performance grading $(P G)[29,30]$ The PG high temperature grading was determined by testing unaged and RTFO (short-term) aged binders as per ASTM D6373 [29], started from $52^{\circ} \mathrm{C}$ with an increment of $6{ }^{\circ} \mathrm{C}$ until the failure criterion $\left(\mathrm{G}^{*} / \sin \delta \leq 1 \mathrm{kPa}\right.$ for unaged or $\leq 2.2 \mathrm{kPa}$ for RTFO aged binders) is reached. The strain levels used for unaged and RTFO (short-term aged) samples were $12 \%$ and $10 \%$, respectively. The PAV (longterm) aged binder was used to determine the PG intermediate temperature by conducting the tests from $31{ }^{\circ} \mathrm{C}$ with a decreased interval of $3{ }^{\circ} \mathrm{C}$ until the failure criterion is reached $\left(\mathrm{G}^{*} \times \sin \delta \geq 5000 \mathrm{kPa}\right)$. The selected strain level for PAV aged sample was $1 \%$. 


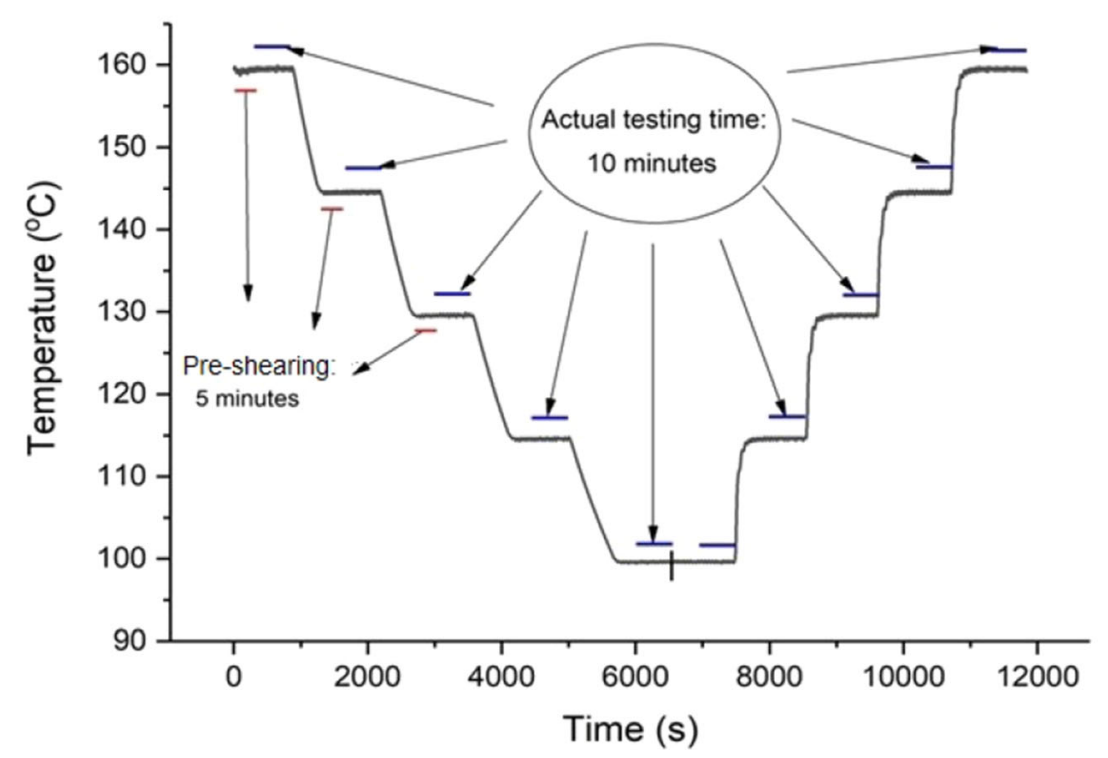

(a) Test protocol

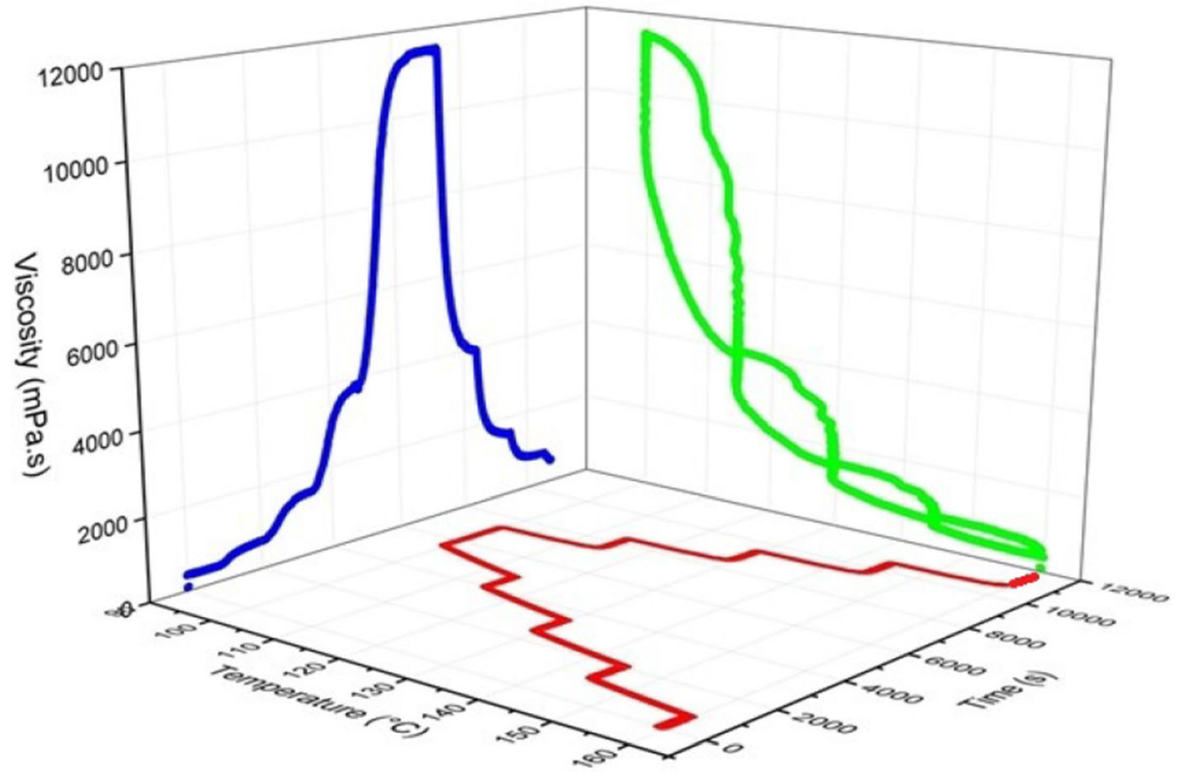

(b) Time, temperature, and viscosity of 3\% LDPE4 blend

Fig. 1 Temperature sweep test protocol and experimental data

To determine the PG low temperature, bending beam rheometer (BBR) was used. The temperature corresponding to a creep stiffness of $\leq 300 \mathrm{MPa}$ and $\mathrm{m}$-value of $\geq 0.3$ were used to assign the PG low temperature grade. In addition, as per AASHTO M332 [30], the traffic grade was assigned based on the nonrecoverable creep compliance value at $\mathrm{PG}$ high temperature obtained from the MSCR test. 


\section{Results and discussion}

\subsection{Optical microscopy- polymer distribution analysis}

The optical micrographs of unmodified binder, LDPE4, LDPE70 and PE wax blends were captured after 30,60, 90, and $150 \mathrm{~min}$ of blending as shown in Figs. 2 and 3. The PE domains started agglomerating within $30 \mathrm{~min}$ of blending and the particle size increased over a period of time (60, 90 and $150 \mathrm{~min})$. As the dosage of LDPE4 increased in the blend, the PE material formed large particles (Fig. 2) whereas the addition of LDPE 70 did not significantly increase the particle size (Fig. 3a-h). The images of 3\% PE wax blended binder are similar to the base Pen 60-70 binder (Fig. 2a). When the PE wax was introduced to LDPE4 blend, the dispersion of the polymer improved in the binder (Fig. 3i-1). In the case of LDPE70, the addition of PE wax did not actually improve the polymer dispersion, and the polymer agglomeration was observed (Fig. 3m-p). At least five images were captured for each blend. The percentage of polymer particle size distribution was analyzed using Imagej and Avizo software.

In this study, the optical microscope images were thresholded to identify the LDPE polymer domains in the asphalt binder. The distinguish between PE domain, and asphalt binder was not only noticed with an optical microscope, but it was also able to identify with Atomic Force Microscope (AFM) analysis, and the images were presented in a recent study conducted by Aljarrah and Masad [25]. From the optical microscope images, the equivalent diameter of LDPE domains was determined and the percentage of polymer particle size distribution was measured through the pixel count. The volume-weighted average diameter $\left(D_{v}\right)$ is calculated using the following Eq. 1.

$D_{v}=W_{v i} D_{i}=\frac{D_{i}^{4}}{\sum_{i}^{N} D_{i}^{3}}$

where $W_{(v, i)}$ is the volume fraction of PE domain with diameter $D_{i}, W_{(v, i)}=\frac{v_{i}}{\sum_{i}^{N} v_{i}}=\frac{D_{i}^{3}}{\sum_{i}^{N} D_{i}^{3}}$.

As the dosage (addition level) of LDPE4 increased in the blend, the PE material agglomerated and formed large domains (Fig. 4a) whereas the addition of
LDPE70 did not significantly change the PE domain size (Fig. 4b). As shown in Fig. 4, the polymer agglomeration depends on LDPE's dosage, the melt flow properties of LDPE, and the time duration. This polymer size increased over a period of time, and the shift in the range of polymer size from 30 to $90 \mathrm{~min}$ was $120 \mu \mathrm{m}$ to $173 \mu \mathrm{m}$ for $3 \%$ LDPE4 and $256 \mu \mathrm{m}$ to $292 \mu \mathrm{m}$ for 5\% LDPE4 blend (Fig. 4a). This increase in size of polymer domain size represents the phase separation of LDPE4 and asphalt binder materials [31]. In the case of LDPE70 (Fig. 4b), the polymer domain size was not significantly changed with the polymer dosage, and the average PE domain sizes were between $27-34 \mu \mathrm{m}$ at $30 \mathrm{~min}, 48-52 \mu \mathrm{m}$ at 90 min. This better stability of LDPE70-blend is due to the high MFI of LDPE70. The excellent mobility and flow properties of LDPE70 is because of the shorter molecular chains and lower entanglement density in the melt state compared to LDPE4. This observation agrees with the previous reports that indicated the addition of polymers with a high MFI and low molecular weight could increase the polymer dispersion in the binder $[7,11]$.

To reduce the phase separation and make the polymer and binder more compatible, PE wax was introduced to the blend. With the addition of $\geq 3 \%$ LDPE4 dosage, the polymer agglomeration increased rapidly with time and hence, the total polymer content was limited to 3\% for LDPE4 blends with PE wax. In the case of LDPE70 blends, the total polymer content was limited to 5\% (with or without PE wax), because the polymer agglomeration was not significant up to $5 \%$ dosage.

When $1 \%$ of PE wax was introduced to $2 \%$ LDPE4 blend, the dispersion of the polymer in the binder improved, as shown in Fig. 4a. For the 3\% LDPE4 blend, the diameter of the polymer domains was $\approx 120$ $\mu \mathrm{m}$ after $30 \mathrm{~min}$ and reduced to $59 \mu \mathrm{m}$ after adding $1 \%$ PE wax to the blend. A similar finding was reported in the work conducted by $\mathrm{Ho}$ et al. [7]. In case of LDPE70, the addition of wax obstructed the uniform dispersion of LDPE70. The polymer diameter of $4 \%$ LDPE70+1\%PE wax was higher than that of the 5\%LDPE70 blend (Fig. 4b). This could be due to the inherent flow properties of the high MFI LDPE70. 


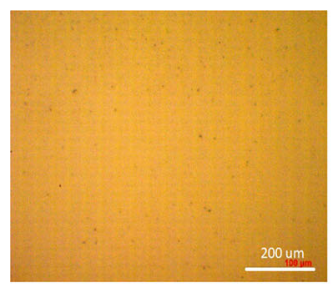

(a) pen 60-70 base binder

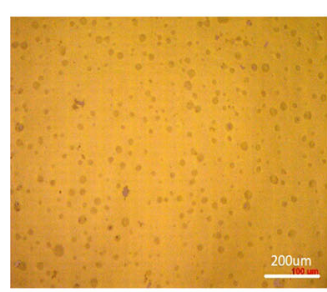

(b) 1\% LDPE4, $30 \mathrm{~min}$

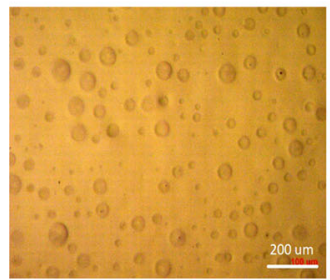

(f) $2 \% \mathrm{LDPE} 4,30 \mathrm{~min}$

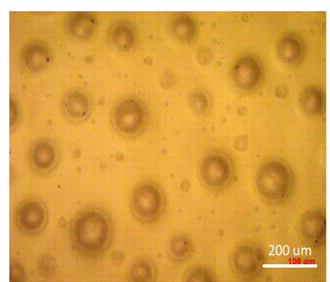

(j) 3\% LDPE4, $30 \mathrm{~min}$

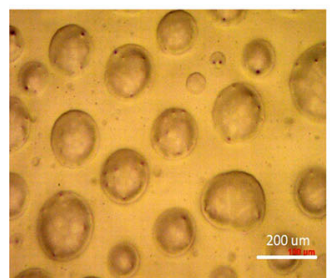

(n) $4 \%$ LDPE4, $30 \mathrm{~min}$

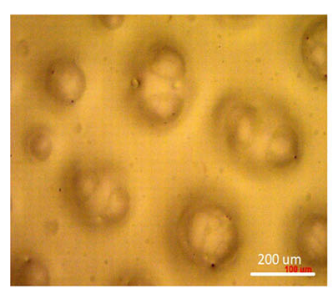

(r) $5 \%$ LDPE4, $30 \mathrm{~min}$

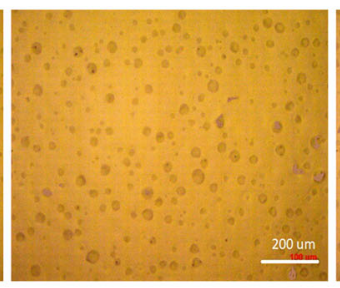

(c) 1\% LDPE4, $60 \mathrm{~min}$

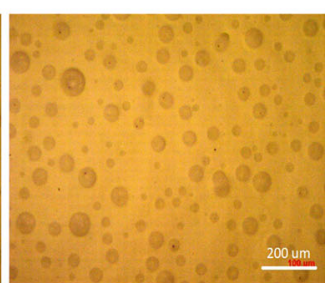

(g) 2\% LDPE4, $60 \mathrm{~min}$

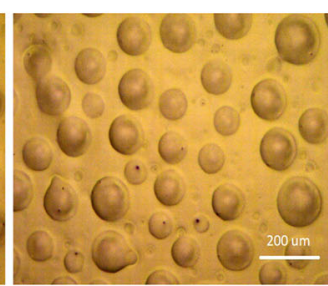

(k) 3\% LDPE4, $60 \mathrm{~min}$

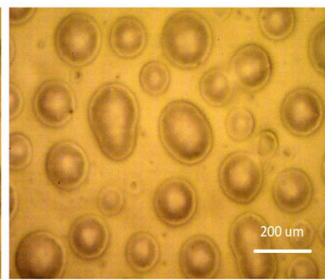

(o) 4\% LDPE4, $60 \mathrm{~min}$

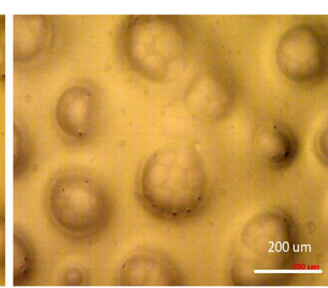

(s) 5\% LDPE4, $60 \mathrm{~min}$

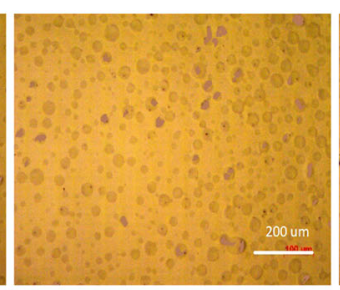

(d) 1\% LDPE4, $90 \mathrm{~min}$

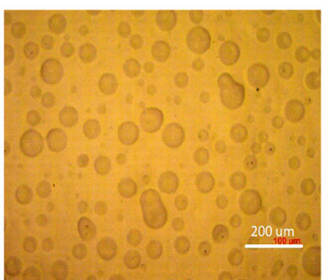

(h) 2\% LDPE4, $90 \mathrm{~min}$

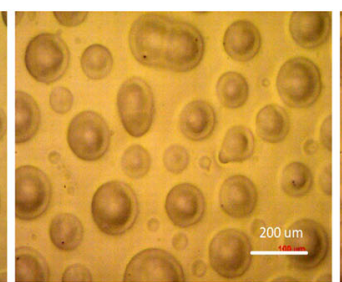

(I) 3\% LDPE4, $90 \mathrm{~min}$

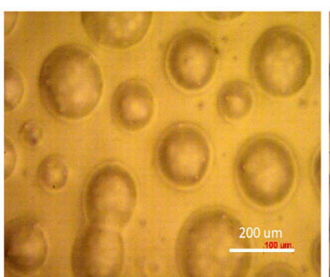

(p) 4\% LDPE4, $90 \mathrm{~min}$

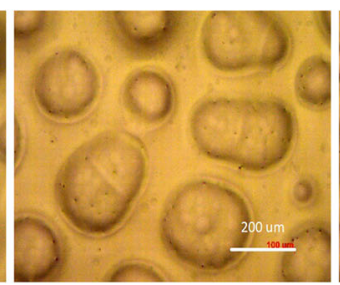

(t) 5\% LDPE4, $90 \mathrm{~min}$

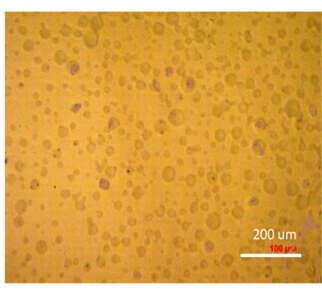

(e) 1\% LDPE4, $150 \mathrm{~min}$

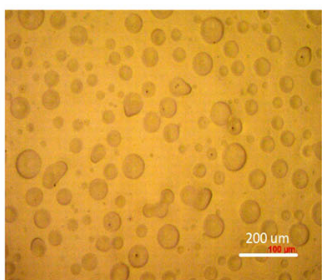

(i) 2\% LDPE4, $150 \mathrm{~min}$

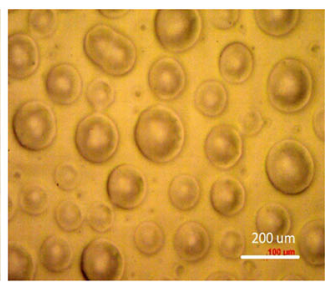

(m) 3\% LDPE4, $150 \mathrm{~min}$

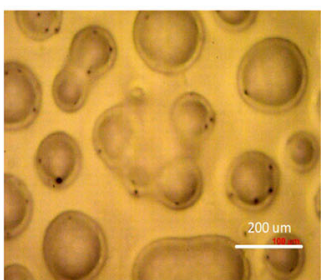

(q) 4\% LDPE4, $150 \mathrm{~min}$

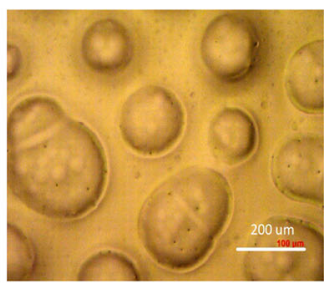

(u) 5\% LDPE4, $150 \mathrm{~min}$ 
4Fig. 2 Optical images of base binder \& LDPE4- binder composites as a function of dosage and storage time

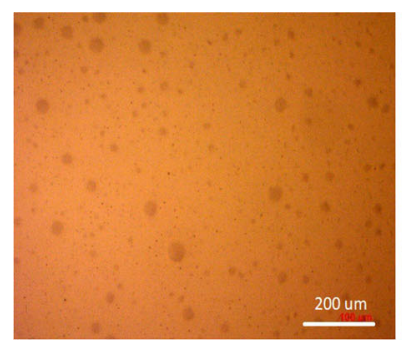

(a) 3\% LDPE70, $30 \mathrm{~min}$

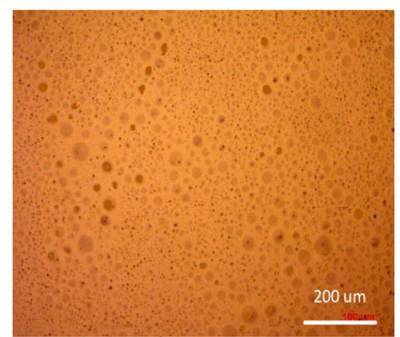

(e) 5\% LDPE70, $30 \mathrm{~min}$

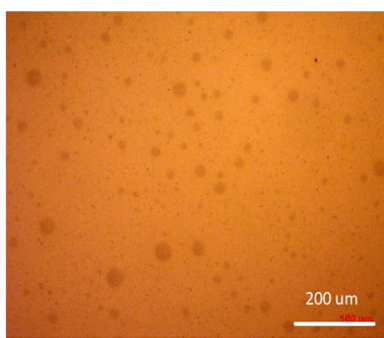

(b) 3\% LDPE70, $60 \mathrm{~min}$

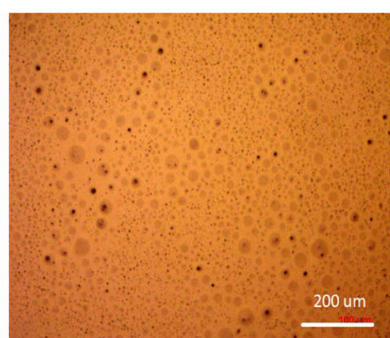

(f) $5 \%$ LDPE70, $60 \mathrm{~min}$

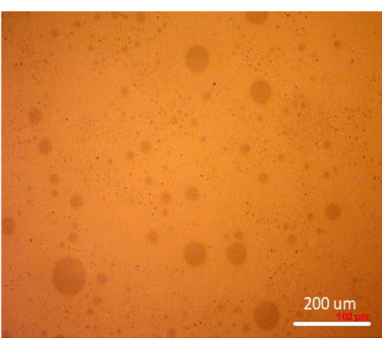

(c) 3\% LDPE70, $90 \mathrm{~min}$

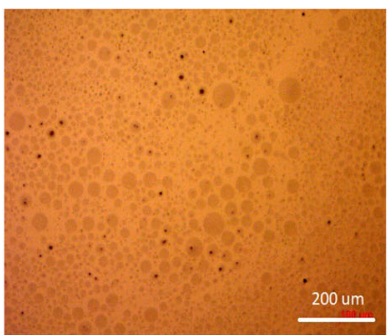

(g) 5\% LDPE70, $90 \mathrm{~min}$

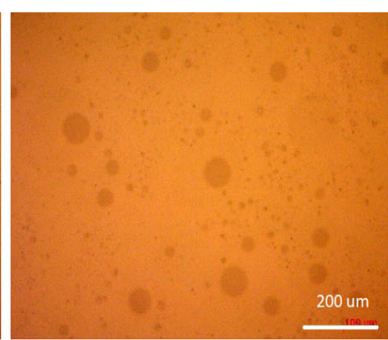

(d) 3\% LDPE70, $150 \mathrm{~min}$

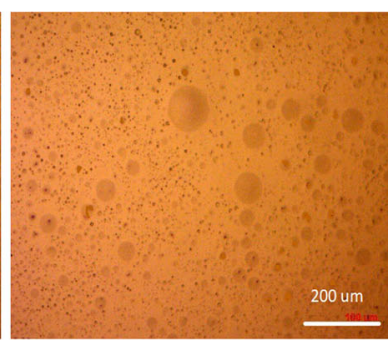

(h) 5\% LDPE70, $150 \mathrm{~min}$
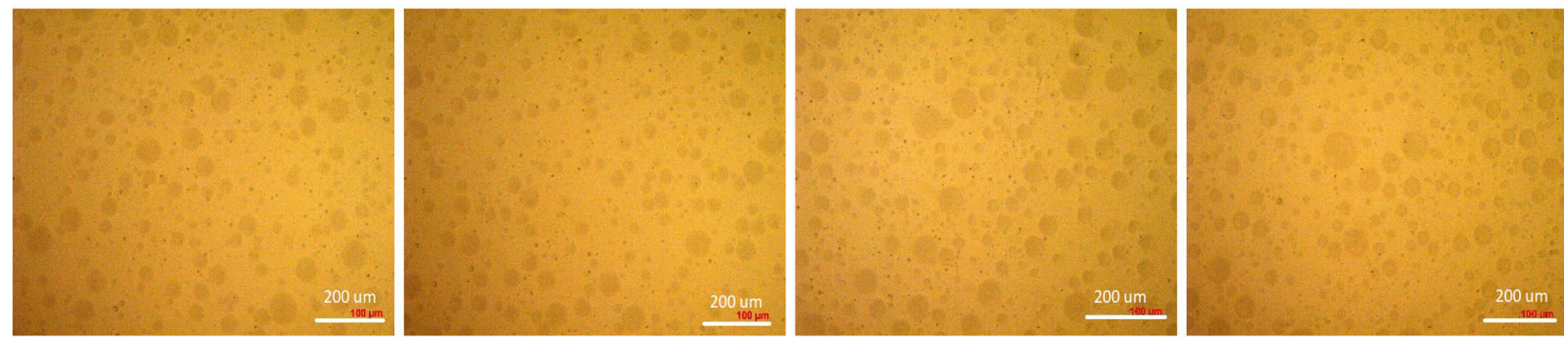

(i) $2 \%$ LDPE4+ $1 \%$ PE wax, (j) $2 \%$ LDPE4+ $1 \%$ PE wax, (k) 2\% LDPE4+ $1 \%$ PE wax, (l) $2 \%$ LDPE4+ $1 \%$ PEwax, $30 \mathrm{~min}$ $60 \mathrm{~min}$ 90 min $150 \mathrm{~min}$
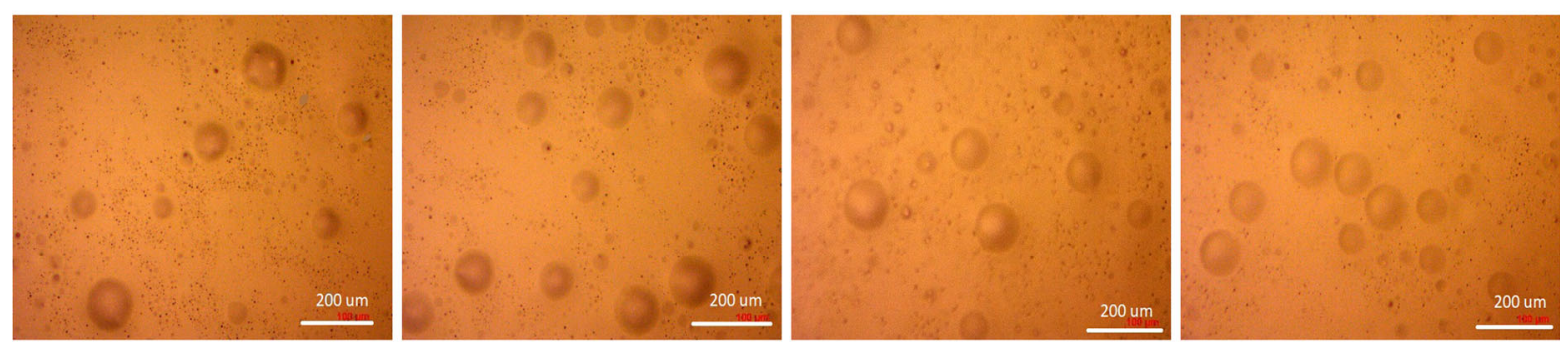

(m) 4\% LDPE70+1\% PE wax, (n) 4\% LDPE70+1\% PE wax, (o) 4\% LDPE70+1\% PE wax, (p) 4\% LDPE70+1\% PE wax, $30 \mathrm{~min}$ $60 \mathrm{~min}$ $90 \mathrm{~min}$ $150 \mathrm{~min}$

Fig. 3 Optical microscopy images of LDPE70 blends, LDPE4+PE wax, LDPE70+PE wax blended binder samples 


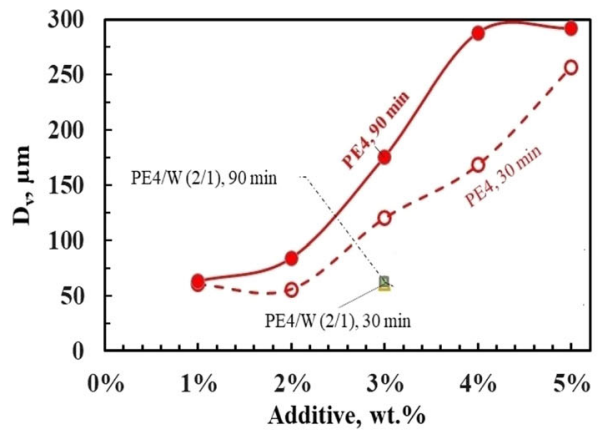

(a) LDPE4 blends

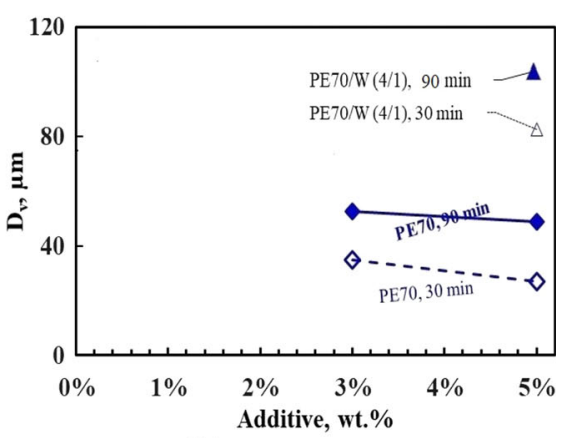

(b) LDPE70 blends

Fig. 4 Volume-weighted average polymer diameter (PE4_LDPE4; PE70—LDPE70; PE4/W(2/1)—2\%LDPE4+1\%wax; PE70/W(4/ 1) $-4 \%$ LDPE70+1\% wax)

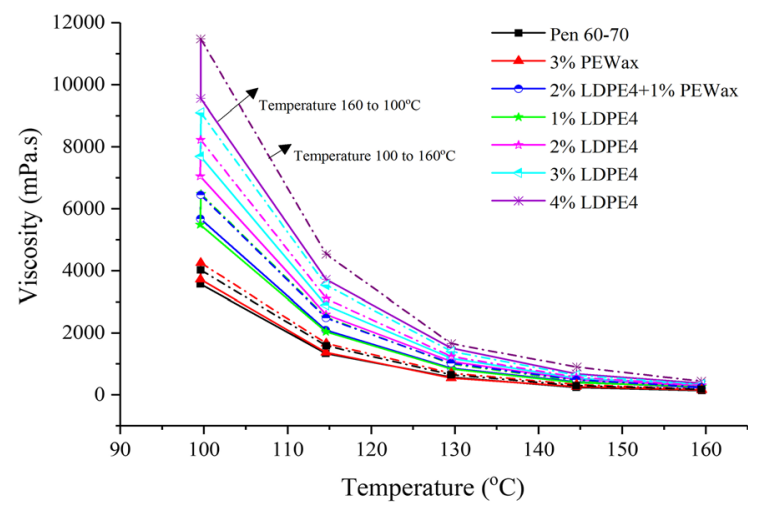

(a) LDPE4 blends

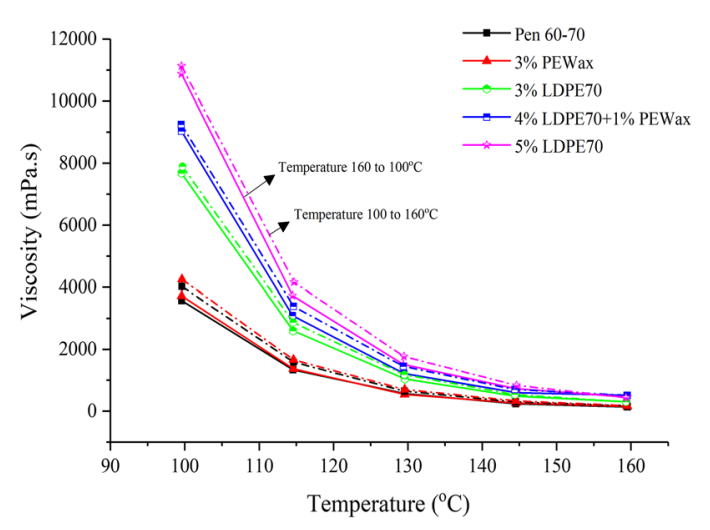

(b) LDPE70 blends

Fig. 5 Viscosity of PE blended binders

\subsection{Viscosity-temperature profile}

Figure 5 shows the average viscosity of LDPE4 and LDPE70 blends. This test was not conducted for 5\% LDPE4 binder because it was too viscous, and the torque value exceeded the allowable limit of $90 \%$ at $100{ }^{\circ} \mathrm{C}$ with the same spindle speed of $20 \mathrm{rpm}$. For each blend, two viscosity curves can be seen in Fig. 5 . The lower viscosity curve was obtained during temperature decrement $\left(160-100^{\circ} \mathrm{C}\right)$, and the upper curve was captured during temperature increment $\left(100\right.$ to $\left.160^{\circ} \mathrm{C}\right)$. As the LDPE dosage increased, a significant difference in the viscosity values was identified during the temperature decrement and increment. The area between these two curves and the normalized area values are plotted in Fig. 6.

As shown in Fig. 6, the area between the viscosity curves increased with the LDPE4 dosage. The $4 \%$ LDPE4 binder area was 3.4 times higher than that of the base Pen $60-70$ binder. It is worth noticing that the high viscous flow activation energy and non-newtonian behaviour of the polymer in the binder blend. The binder blend system might undergo some structural changes as a function of temperature, and hence the area under the viscosity-temperature hysteresis loop curve increases with the increase of polymer content in the binder blend. This phenomenon depends on polymer type, molecular weight $\left(M_{w}\right)$ and molecular weight distribution (MWD). The 3 and 5\% LDPE70 blends' area did not significantly vary due to the higher MFI of LDPE70.

The addition of PE wax reduced the viscosity of LDPE4/70 blends. The viscosity hysteresis area of the $3 \%$ LDPE4 blend was 2.6 times the area of the Pen 60-70 binder, while the area of the $2 \%$ LDPE $4+1 \%$ PE wax was only 1.5 times that of the Pen 60-70 binder. The large hysteresis area represents the instability of the blends with higher percentages of LDPE4. In addition, the improved stability of LDPE4 blend with 


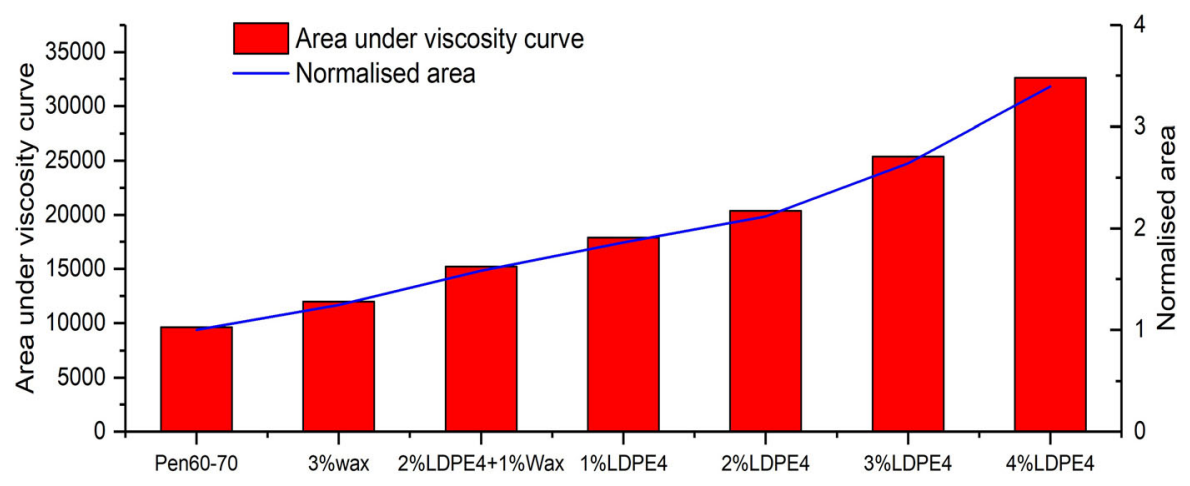

(a) LDPE4 blends

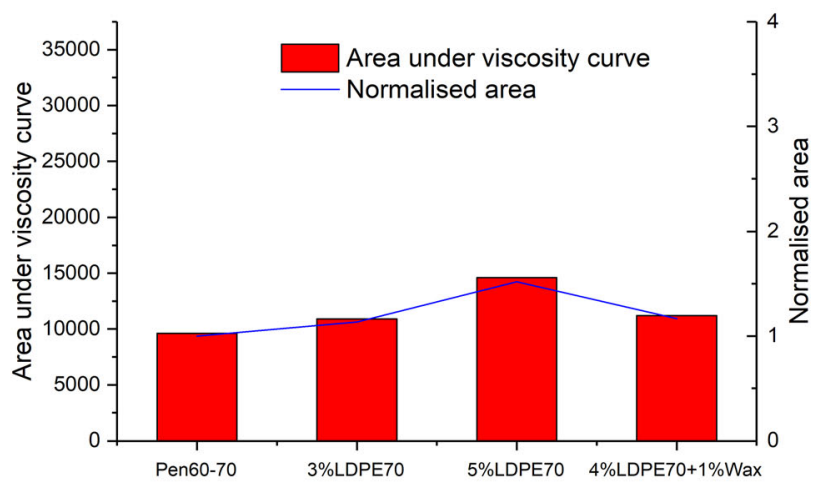

(b) LDPE70 blends

Fig. 6 Area under viscosity hysteresis curves

the addition of PE wax is confirmed by the lower hysteresis area.

The high-temperature behavior of the LDPE70 blend (with or without PE wax) was not significantly influenced by the polymer dosage. From Fig. 6, the area of the viscosity hysteresis increased gradually with LDPE content up to 3\% LDPE4 content; after that, a rapid increment was observed. The addition of LDPE70 did not significantly change the viscosity hysteresis area with dosage. Hence, we limited the dosage of LDPE4 to $3 \%$ with PE wax and LDPE70 to 5\% (with or without PE wax). For further study, Pen 60-70, 3\% LDPE4, 5\% LDPE4, 3\% LDPE70, 5\% LDPE70, 2\% LDPE4+1\% PE wax, 4\% LDPE4+1\%PE wax and 3\% PE wax binders are analyzed.

\subsection{Frequency sweep test-dynamic modulus}

At each temperature of $25,35,45,55$, and $65^{\circ} \mathrm{C}$, the storage (G') and loss modulus (G') values were recorded, and the dynamic modulus $\left(\left|G^{*}\right|\right)$ and the phase angle $(\delta)$ were calculated. The dynamic modulus curves were shifted to a reference temperature of $35^{\circ} \mathrm{C}$ using RHEA software [32] as shown Fig. 7. From Fig. 7a, the Pen 60-70 base binder has the lowest dynamic modulus and the modulus of $3 \% \mathrm{PE}$ wax and $2 \%$ LDPE4+ $1 \%$ PE wax seem to be identical.

The addition of a low molecular weight PE wax softens the binder blend, which lowers the dynamic modulus. Above 3\% LDPE4 dosage, there is no change in the dynamic modulus of LDPE4 blends. In the case of LDPE70 blends (Fig. 7b), the 3\% LDPE70 has the lower dynamic modulus values than the $3 \% \mathrm{PE}$ wax blend at lower frequencies and the modulus of 5\% LDPE70 and $4 \%$ LDPE70+1\% PE wax blends were approximately the same. As the $\Delta H_{f}$ of these blends is very close, the crystalline structures form physical cross-links in the amorphous phase, thus increases the storage modulus and both the loss modulus and phase angle decreases.

In Fig. 7, for constructing master curves at a reference temperature of $35^{\circ} \mathrm{C}$, the temperature dependent shift factors were determined using WLF Eq. 2 [33]. 


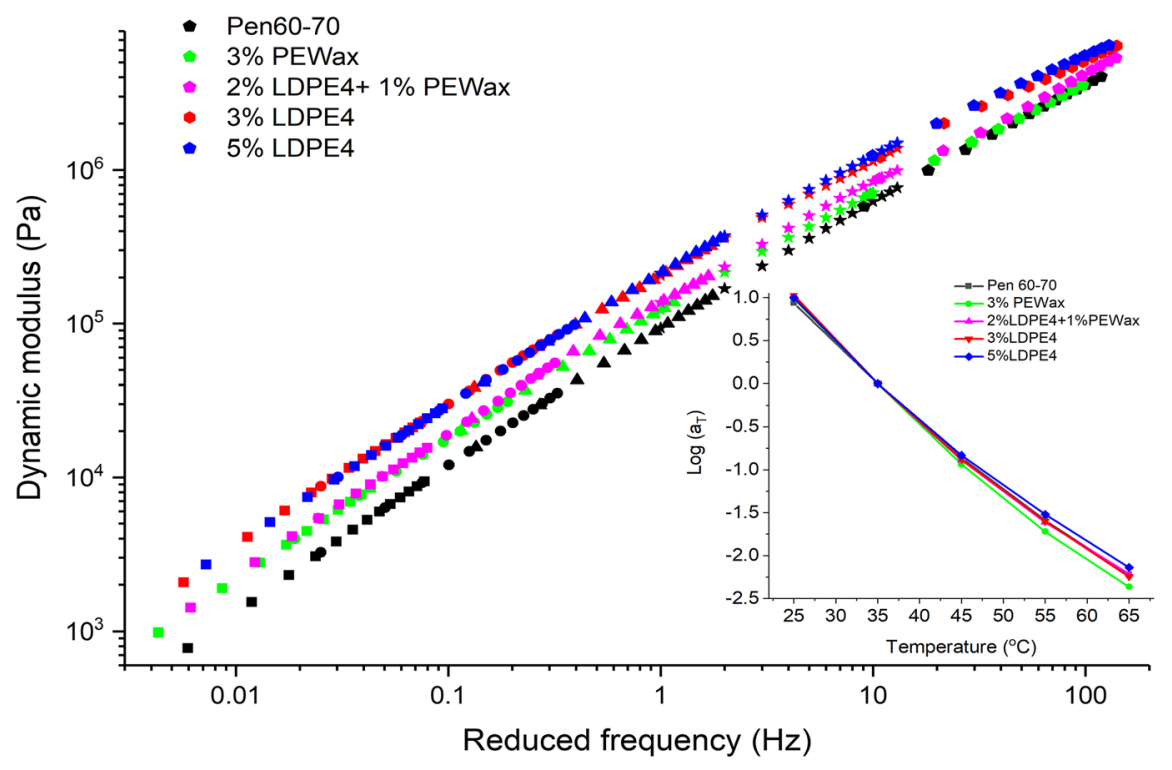

(a) LDPE4 blends

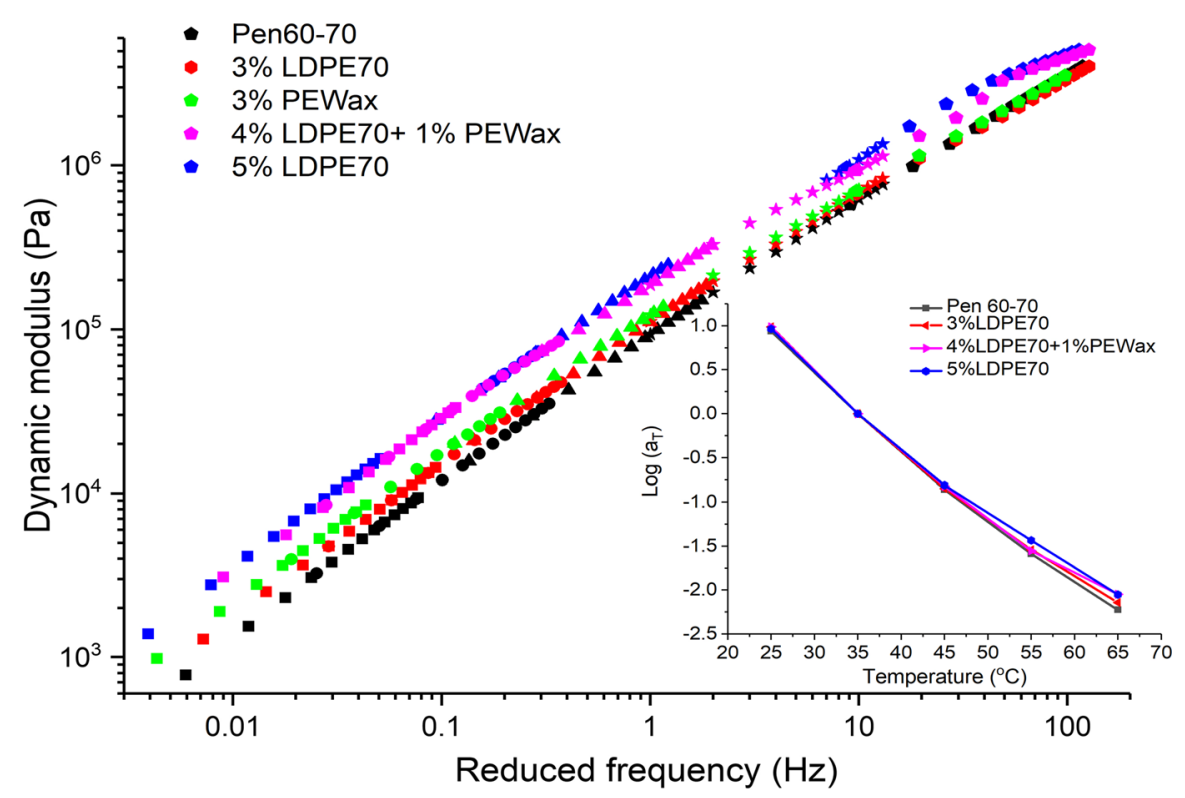

(b) LDPE70 blends

Fig. 7 Master curves of dynamic modulus at $35^{\circ} \mathrm{C}$ versus frequency calculated using TTS of data measured at $25^{\circ} \mathrm{C}$ (pentagon), $35^{\circ} \mathrm{C}$ (star), $45^{\circ} \mathrm{C}$ (triangle), $55^{\circ} \mathrm{C}$ (circle), and $65^{\circ} \mathrm{C}$ (square), shift factors in subplots

$$
\log a_{T}=\frac{C_{1}\left(T-T_{o}\right)}{C_{2}+\left(T-T_{o}\right)}
$$

where $a_{T}$ is the shift factor; $\mathrm{T}$ is the temperature in ${ }^{\circ} \mathrm{C}$; $\mathrm{T}_{\mathrm{o}}$ is the reference temperature; $C_{1}$ and $C_{2}$ are constants. First, the temperature isotherms were shifted to a known reference temperature and the horizontal shift factors were determined using the time-temperature superposition principle (TTSP). Then, the material constants $C_{1}$ and $C_{2}$ were determined by fitting shift factors against temperatures. 
Using these constants, the master curve can be constructed at any reference temperature, and the temperature-dependent shift factors are presented in inset plots of Fig. 7. The LDPE blended binders have the least slope of shift factors. Based on the slope of the shift factors, 3\% PE wax binder has more temperature susceptibility whereas the addition of LDPE4 and LDPE70 reduced the temperature susceptibility of the binders.

\subsection{Multiple stress creep and recovery Test}

Figure 8a, b show the strain response during the creep and recovery cycles of LDPE4 and LDPE70 blends at $64^{\circ} \mathrm{C}$. Out of all binders, the unmodified binder has higher strain values. With the addition of higher dosage of LDPE4 and LDPE70, the total strain was reduced. In Fig. 8b, the identical strain response of 3\% PE wax and 3\% LDPE70, 4\% LDPE70+1\% PE wax and 5\% LDPE70 was seen.

The non-recoverable creep compliance $\left(J_{n r}\right)$ values were calculated for PE-binder blends by following the equations given in ASTM D7405 [27] and the obtained values are presented in Fig. 9. The results indicate that the $J_{n r}$ values decreased with increase in the dosage of LDPE 4 and LDPE70. The inclusion of polymeric chains in the asphalt binder restricts the deformation and is in proportion to the molecular weight of polymers. High molecular weight LDPE4 restricts the deformation more when compared to low molecular weight LDPE70 polymer. When compared LDPE4 and LDPE70 binders in the inset plot (Fig. 9), the $J_{n r}$ values of 3\% and 5\% LDPE70 binders were slightly higher than 3\% and 5\% LDPE4 binders. However, the difference was not as significant as the $J_{n r}$ values of all four samples were less than $1.5 \mathrm{kPa}^{-1}$. As per AASHTO M332 [30], at $64{ }^{\circ} \mathrm{C}$, the traffic grade of 5\% LDPE4 was ' $\mathrm{E}$ ' which represents extremely heavy traffic and the remaining three binders $(3 \%$ LDPE4/70, 5\% LDPE70) have ' $\mathrm{V}$ ' grade that represents very heavy traffic.

\subsection{Linear strain amplitude sweep test}

For determining the fatigue life of binders, the slope of storage modulus was determined from the frequency sweep test, and the damage accumulation was calculated from the linear strain amplitude sweep test data.
Figure 10 shows the applied shear stress and the calculated dynamic modulus values plotted against the increased strain amplitude (0-30\%). In Fig. 10a, the stress increased up to a specific strain value, thereafter a sudden drop was seen, whereas the dynamic modulus values gradually decreased (Fig. 10b). The fatigue failure point was defined as the cycle corresponding to the 1 . peak shear stress (or) $2.50 \%$ reduction in the dynamic modulus values whichever occurs first.

From Fig. 10a, 5\%LDPE4 sample was able to take more oscillatory load, and at the same time, a sudden drop in the stress values was observed from the peak point. Though the dynamic modulus of LDPE70 blends was lower than LDPE4 blends, the rate of reduction in the oscillatory stress was slow for LDPE70 blends.

As described in AASHTO TP101 [28], the LAS test data were analyzed using the Viscoelastic Continuum Damage Theory (VECD) [34]. The damage accumulation of the PE-binder blends was calculated using Eq. 3.

$$
D(t) \cong \sum_{i=1}^{N}\left[\pi \gamma_{o}^{2}\left(C_{i-1}-C_{i}\right)\right]^{\frac{\alpha}{1+\alpha}}\left(t_{i}-t_{i-1}\right)^{\frac{1}{1+\alpha}}
$$

where $\mathrm{t}$ is time in seconds. $\gamma_{o}$ is applied strain (\%). $C(t)=\frac{\left|G^{*}\right|(t)}{\left|G^{*}\right|_{\text {initial }}} . \alpha$ is inverse slope of the storage modulus. The damage at failure point $\left(D_{f}\right)$ was calculated from the $\mathrm{C}(\mathrm{t})$ at peak shear stress (or) at $50 \%$ reduction in dynamic modulus, whichever occurs first. The equation used to calculate the fatigue life $N_{f}$ was $N_{f}=A\left(\gamma_{\max }\right)^{-B}$, where $A=\frac{f D_{f}^{k}}{k\left(\pi C_{1} C_{2}\right)^{\alpha}}, B=2 \alpha$ and $\gamma_{\max }$ is the binder strain $(2.5,5 \%)$.

Figure 11 shows the fatigue life determined at the strain levels of 2.5 and $5 \%$. The fatigue performance of LDPE70 blends was better than the LDPE4 blends. High molecular weight and densely packed molecules in LDPE4 decrease the mobility of the polymer chains during fatigue loading, leading to brittle failure. On the contrary, LDPE70 with low molecular weight has increased chain mobility, leading to experience shear yield and ductile failure. This type of failure phenomenon favors the low $M_{w}$ LDPE for improved fatigue life compared to high $M_{w}$ LDPE. With an increased dosage of LDPE70, the ductile-brittle transition occurs at an early stage, and hence 5\%LDPE70 binder blend shows less fatigue life than 3\%LDPE70. The 3\% LDPE70 blend has greater fatigue life than the 


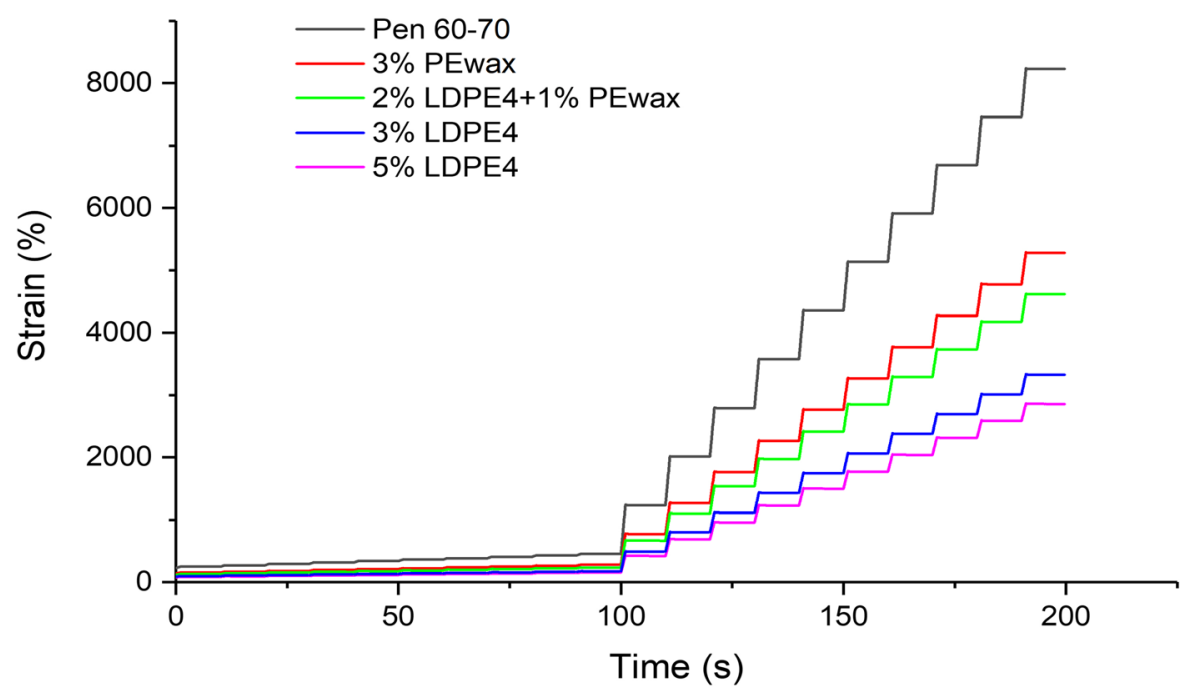

(a) LDPE4 blends

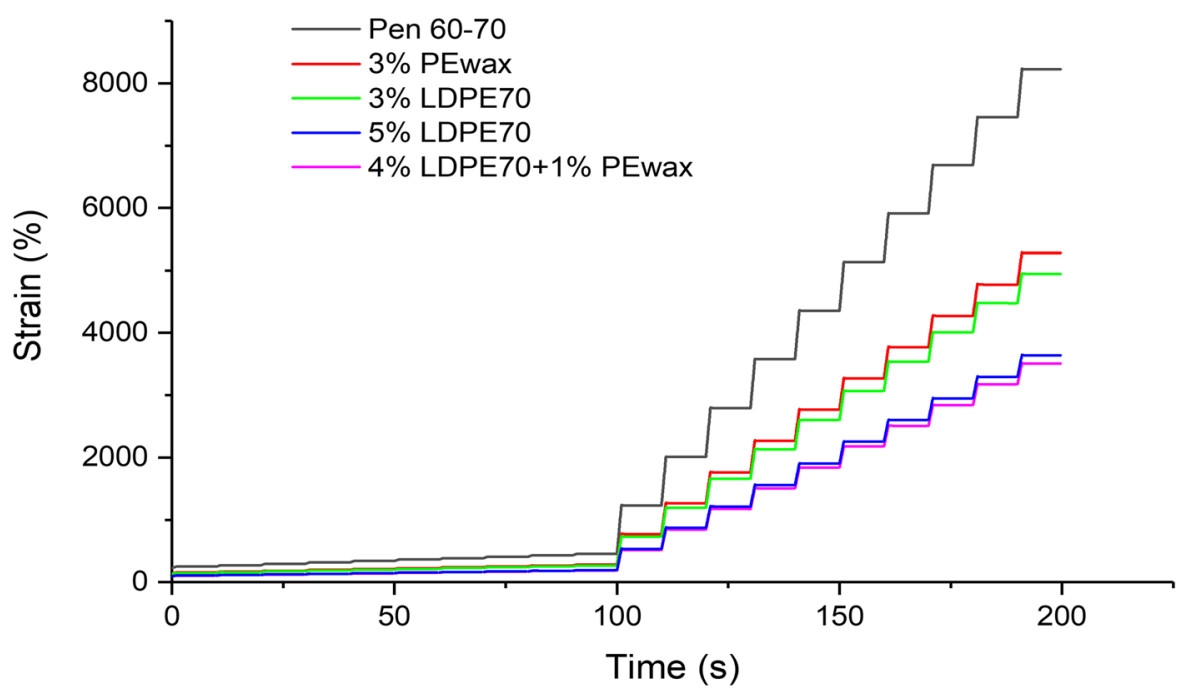

(b) LDPE70 blends

Fig. 8 Strain response during creep and recovery cycles at $64{ }^{\circ} \mathrm{C}$

remaining binders. A similar low temperature performance was confirmed for the 3\% LDPE70 blend by the performance grading test discussed in the following section.

\subsection{Performance grading-temperature sweep test}

The critical PG high temperatures were determined based on the $G^{*} / \sin \delta$ value of $1 \mathrm{kPa}$ for unaged binders and $2.2 \mathrm{kPa}$ for RTFO aged binders. The binders have $\mathrm{PG}$ continuous temperature in the range of $67-74.9^{\circ} \mathrm{C}$ for unaged binders, and $66.7-75.6^{\circ} \mathrm{C}$ for RTFO aged binders (Table 2). However, for Pen 60-70 and $3 \%$ wax blend, the continuous temperatures were less than $70^{\circ} \mathrm{C}$ and these binders were graded as PG64 and all the remaining binders were graded as PG70. The PG intermediate continuous temperature was in the range of $23.9-30.2^{\circ} \mathrm{C}\left(G^{*} / \sin \delta\right.$ is 5000 $\mathrm{kPa})$. 


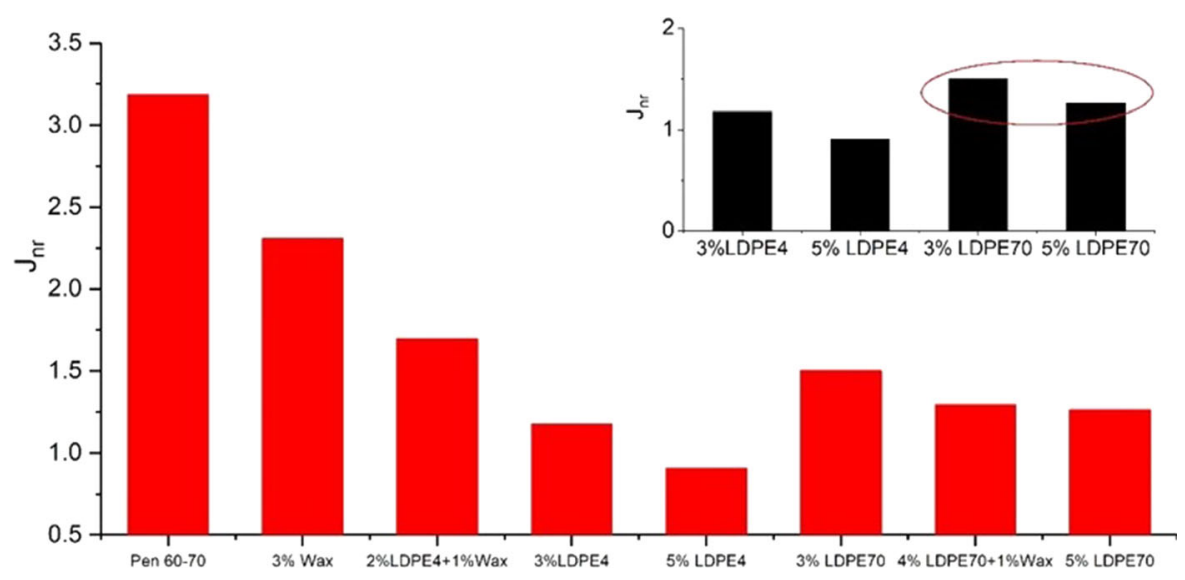

Fig. 9 Non-recoverable creep compliance $\left(J_{n r}\right)$ at $64^{\circ} \mathrm{C}$

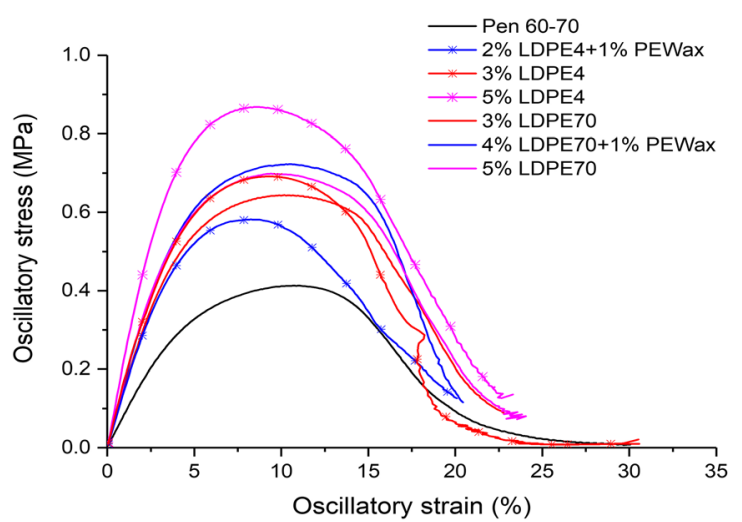

(a) Oscillatory stress versus strain (\%)

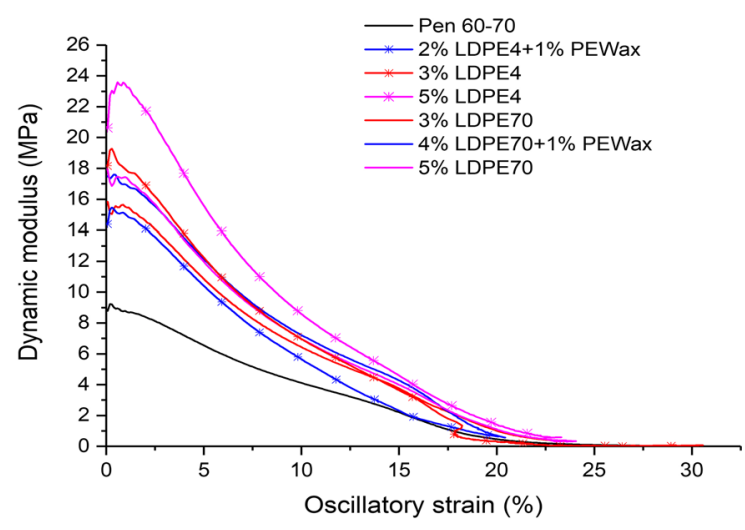

(b) Dynamic modulus versus strain (\%)

Fig. 10 Stress, strain and dynamic modulus values in LAS test

The BBR failure temperature for Pen $60-70$ and 3\% LDPE70 binders were $-12^{\circ} \mathrm{C}$ (temperature corresponding to stiffness $\leq 300 \mathrm{MPa}$, slope $\geq 0.3$ ) and their PG low-temperature grade was $-22^{\circ} \mathrm{C}$. All the remaining LDPE blends have a PG low temperature of $-16^{\circ} \mathrm{C}$ (BBR failure temperature is $-6^{\circ} \mathrm{C}$ ). Based on the non-recoverable creep compliance $\left(J_{n r}\right)$ value, the standard traffic grade ' $\mathrm{S}$ ' was assigned because all the binders have $\left(J_{n r}\right)$ values greater than $2 \mathrm{kPa}^{-1}$ at their PG high-temperature. Out of all the binders, the $3 \%$ LDPE70 content has improved both the high and lowtemperature performance characteristics (PG 70S-22), and its low-temperature $\mathrm{PG}$ grade was the same as that of the Pen 60-70 base binder.

\section{Conclusions}

In this study, polyethylene (PE) modified binders were prepared with various wt\% compositions of LDPE polymers. PE wax was also added in certain wt $\%$ to improve the polymer dispersion and to reduce the agglomeration. The interaction between the LDPE chains and the asphalt binder was analyzed using thermal stability, microscopic, rheological, and mechanical tests. Based on the polymer particle size analysis and viscosity profiles, selected dosages of LDPE4 and LDPE70 were used for the rheological and mechanical testing. Based on the obtained results, the following conclusions are drawn:

- From thermo-mechanical properties, the blends containing LDPE4 have a higher melting point and heat of fusion than LDPE70 blends. The addition of PE wax to the LDPE blends significantly influenced the enthalpy, which could negatively 


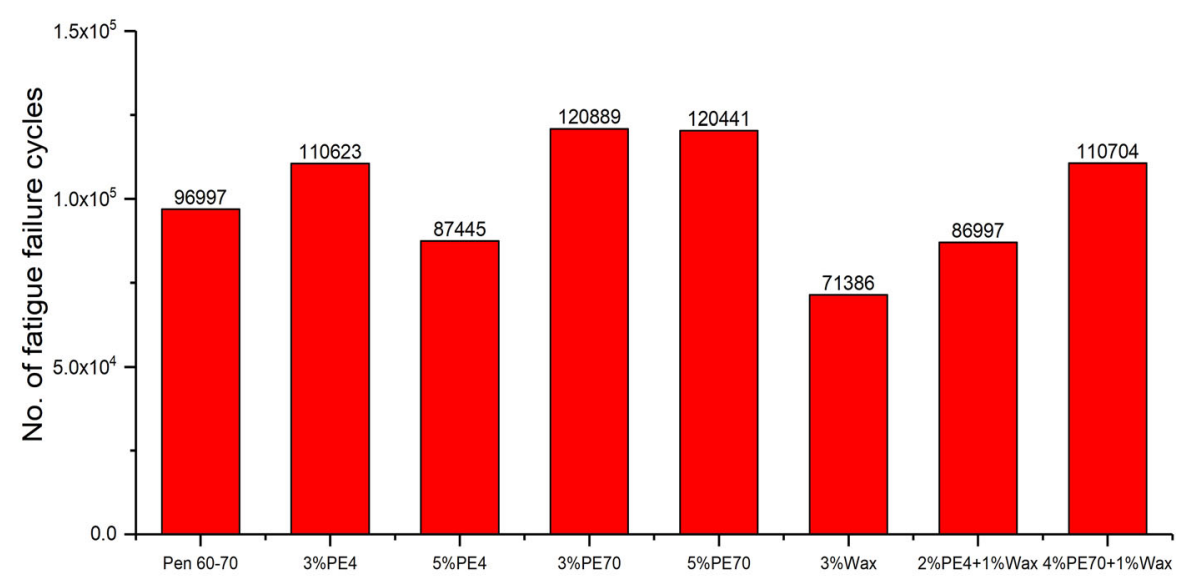

(a) $2.5 \%$ strain

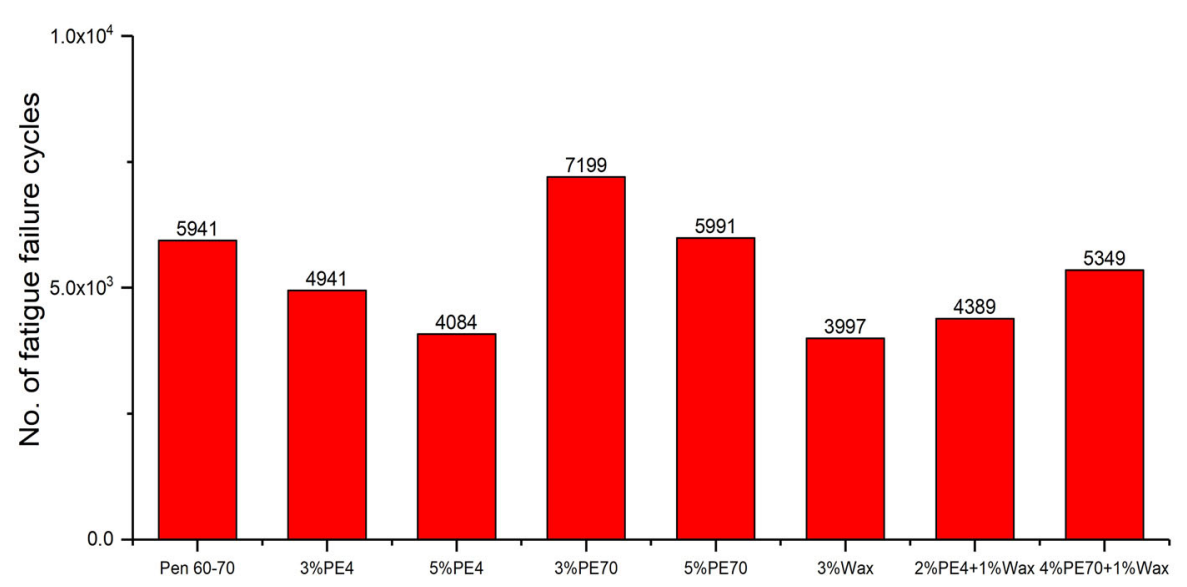

(b) $5 \%$ strain

Fig. 11 No. of fatigue failure cycles of LDPE blends

impact the low-temperature properties of the blend containing PE wax.

- The polymer dispersity in the binder was highly dependent on the dosage level of the polymer and storage time. In the case of LDPE4, the polymer content was limited to $3 \%$, above which a large size polymer agglomerates were observed. The addition of a higher dosage of LDPE70 (5\%) did not significantly influence the polymer particle (domain) size distribution.

- The addition of PE wax to the LDPE4 blend improved the polymer dispersity but did not improve the dispersity of the LDPE70 polymer due to the inherent flow properties of the high MFI LDPE70 polymer.
- The area of the viscosity hysteresis curves increased gradually with LDPE4 loading up to $3 \%$, thereafter a rapid increase was observed. The addition of higher dosages of LDPE70 (3-5\%) did not significantly change the area of viscosity hysteresis. Hence, the dosage of LDPE4 was limited to 3\% (with PE wax) and LDPE70 to 5\% (with or without PE wax).

- The LDPE4 blends with greater than $3 \%$ dosage have similar dynamic modulus values. The stiffness of LDPE70 blend was lower than that of the PE wax blend. From the slope of the shift factors versus temperature, the LDPE blended binders have lower temperature susceptibility than the base binder. 
Table 2 Performance grade of different binders

\begin{tabular}{|c|c|c|c|c|c|c|c|c|}
\hline Parameter & Pen $60-70$ & $3 \%$ Wax & $\begin{array}{l}2 \% \text { LDPE4+ } \\
1 \% \text { wax }\end{array}$ & 3\%LDPE4 & $5 \%$ LDPE4 & $3 \%$ LDPE70 & $\begin{array}{l}4 \% \text { LDPE70+ } \\
1 \% \text { wax }\end{array}$ & $5 \%$ LDPE70 \\
\hline PG HCT (unaged) & 67 & 68 & 70.9 & 72.4 & 74.1 & 70.9 & 73.2 & 74.9 \\
\hline PG HCT (RTFO) & 66.7 & 68.6 & 71.1 & 73.60 & 75.6 & 71.6 & 72.4 & 73.1 \\
\hline PG high grade & 64 & 64 & 70 & 70 & 70 & 70 & 70 & 70 \\
\hline PG ICT (PAV) & 23.9 & 25.2 & 27.4 & 27.4 & 30.1 & 27.6 & 29.8 & 30.2 \\
\hline $\begin{array}{l}\text { PG intermediate } \\
\text { grade }\end{array}$ & 25 & 28 & 28 & 28 & 31 & 28 & 31 & 31 \\
\hline BBR failure temp. & -12 & -6 & -6 & -6 & -6 & -12 & -6 & -6 \\
\hline PG low grade & -22 & -16 & -16 & -16 & -16 & -22 & -16 & -16 \\
\hline$J_{n r}$ at PG high & 3.188 & 2.307 & 4.581 & 3.37 & 2.257 & 3.94 & 3.26 & 3.07 \\
\hline PG grade & 64S-22 & $64 S-16$ & $70 S-16$ & $70 S-16$ & $70 S-16$ & 70S-22 & $70 S-16$ & 70S-16 \\
\hline
\end{tabular}

*HCT- high critical temperature, ICT- intermediate critical temperature

- From the MSCR results, the non-recoverable creep compliance decreased with the increase in the dosage of LDPE. However, all the binders' traffic grade was "S" (standard traffic) at their PG high temperatures. At a constant temperature of $64^{\circ} \mathrm{C}$, 5\% LDPE4 has better rut resistance.

- In the LAS test, though the LDPE4 blends could take more oscillatory loading, they failed early at fewer cycles than the LDPE70 blends. The addition of PE wax deteriorated the fatigue life of the LDPE blends. The fatigue performance of the $3 \%$ LDPE70 blend was better than all the remaining binders.

- Among all blend formulation, the 3\% LDPE70 blend has improved both the high and lowtemperature performance characteristics (PG 70S-22), and its low temperature PG grade was the same as the Pen $60-70$ base binder.

Acknowledgements This work was supported by the Qatar National Research Fund (QNRF): NPRP11S-1128-170041. The authors also acknowledge the co-funding of Qatar Petrochemical Company (QAPCO). All the statements are those of the authors.

Funding Open access funding provided by the Qatar National Library.

\section{Declarations}

Conflicts of interest The authors declare that there is no conflict of interest.
Open Access This article is licensed under a Creative Commons Attribution 4.0 International License, which permits use, sharing, adaptation, distribution and reproduction in any medium or format, as long as you give appropriate credit to the original author(s) and the source, provide a link to the Creative Commons licence, and indicate if changes were made. The images or other third party material in this article are included in the article's Creative Commons licence, unless indicated otherwise in a credit line to the material. If material is not included in the article's Creative Commons licence and your intended use is not permitted by statutory regulation or exceeds the permitted use, you will need to obtain permission directly from the copyright holder. To view a copy of this licence, visit http://creativecommons.org/licenses/by/4.0/.

\section{References}

1. Little D, Epps JA (1980) Evaluation of certain structural characteristics of recycled pavement materials. Proc Assoc Asphalt Paving Technol 49:219-251

2. Jew P, Shimizu J, Svazic M, Woodhams R (1986) Polyethylene-modified bitumen for paving applications. J Appl Polym Sci 31:2685-2704

3. Little DN (1991) Performance assessment of binder-rich polyethylene-modified asphalt concrete mixtures (Novophalt). Transportation Research Record (1317)

4. Button JW, Phillips SG (1993) Effect of asphalt additives on pavement performance. Tech. rep.

5. Daly WH, Qui Chiu Z, Negulescu I (1993) Preparation and characterization of asphalt-modified polyethylene blends. Transportation Research Record (1391)

6. Maupin Jr G (1993) Evaluation of a modified asphalt: Novophalt. Tech. rep.

7. Ho S, Church R, Klassen K, Law B, MacLeod D, Zanzotto L (2006) Study of recycled polyethylene materials as asphalt modifiers. Can J Civ Eng 33(8):968-981 
8. Jun L, Yuxia Z, Yuzhen Z (2008) The research of GMA-gLDPE modified qinhuangdao bitumen. Constr Build Mater 22(6):1067-1073

9. Vargas MA, Vargas MA, Sanchez-Solis A, Manero O (2013) Asphalt/polyethylene blends: rheological properties, microstructure and viscosity modeling. Constr Build Mater 45:243-250

10. Fang C, Zhang Y, Yu Q, Zhou X, Guo D, Yu R, Zhang M (2013) Preparation, characterization and hot storage stability of asphalt modified by waste polyethylene packaging. J Mater Sci Technol 29(5):434-438

11. Yousefi AA (2003) Polyethylene dispersions in bitumen: the effects of the polymer structural parameters. J Appl Polym Sci 90(12):3183-3190

12. Polacco G, Berlincioni S, Biondi D, Stastna J, Zanzotto L (2005) Asphalt modification with different polyethylenebased polymers. Eur Polymer J 41(12):2831-2844

13. Saroufim E, Celauro C, Mistretta MC (2018) A simple interpretation of the effect of the polymer type on the properties of PMBs for road paving applications. Constr Build Mater 158:114-123

14. Ouyang C, Wang S, Zhang Y, Zhang Y (2006) Low-density polyethylene/silica compound modified asphalts with hightemperature storage stability. J Appl Polym Sci 101(1):472-479

15. Kalantar ZN, Karim MR, Mahrez A (2012) A review of using waste and virgin polymer in pavement. Constr Build Mater 33:55-62

16. Dalhat M, Al-Abdul Wahhab H (2017) Performance of recycled plastic waste modified asphalt binder in Saudi Arabia. Int J Pavement Eng 18(4):349-357

17. Polacco G, Filippi S, Merusi F, Stastna G (2015) A review of the fundamentals of polymer-modified asphalts: Asphalt/ polymer interactions and principles of compatibility. Adv Colloid Interface Sci 224:72-112

18. Murphy M, O'mahony M, Lycett C, Jamieson I, (2001) Recycled polymers for use as bitumen modifiers. J Mater Civ Eng 13(4):306-314

19. Hussein IA, Iqbal MH, Al-Abdul-Wahhab HI (2005) Influence of Mw of LDPE and vinyl acetate content of EVA on the rheology of polymer modified asphalt. Rheol Acta 45(1):92-104

20. Ghuzlan KA, Al-Khateeb GG, Qasem Y (2013) Rheological properties of polyethylene-modified asphalt binder. In: 3rd annual international conference on civil engineering-ATINER, Athens, Greece

21. Upadhyay S, Mallikarjunan V, Subbaraj VK, Varughese S (2008) Swelling and diffusion characteristics of polar and nonpolar polymers in asphalt. $J$ Appl Polym Sci 109(1):135-143

22. Punith V, Veeraragavan A (2007) Behavior of asphalt concrete mixtures with reclaimed polyethylene as additive. J Mater Civ Eng 19(6):500-507
23. Liang M, Xin X, Fan W, Zhang J, Jiang H, Yao Z (2019) Comparison of rheological properties and compatibility of asphalt modified with various polyethylene. Int $\mathrm{J}$ Pavem Eng 1-10

24. Yeh PH, Nien YH, Chen JH, Chen WC, Chen JS (2005) Thermal and rheological properties of maleated polypropylene modified asphalt. Polym Eng Sci 45(8):1152-1158

25. Aljarrah MF, Masad E (2020) Nanoscale viscoelastic characterization of asphalt binders using the AFM-nDMA test. Mater Struct 53(4):1-15

26. Roja KL, Masad E, Vajipeyajula B, Yiming W, Khalid E, Shunmugasamy VC (2020) Chemical and multi-scale material properties of recycled and blended asphalt binders. Constr Build Mater 261:119689

27. ASTM D7405-20 (2020) Standard test method for multiple stress creep and recovery (MSCR) of asphalt binder using a dynamic shear rheometer. ASTM International, West Conshohocken, PA

28. AASHTO TP 101-13 (2013) Estimating damage tolerance of asphalt binders using the linear amplitude sweep. American Association of State Highway and Transportation Officials, Washington, D.C, USA

29. ASTM D6373-16 (2016) Standard specification for performance graded asphalt binder. ASTM International, West Conshohocken, PA, www.astm.org

30. AASHTO M 332-14 (2014) Specification for performance based asphalt binder using multiple stress creep recovery (MSCR) test. American Association of State Highway and Transportation Officials, Washington, D.C, USA

31. Liang M, Xue X, Fan W, Wang H, Jiang H, Zhang J, Yao Z (2019) Phase behavior and hot storage characteristics of asphalt modified with various polyethylenes: Experimental and numerical characterizations. Constr Build Mater 203:608-620

32. RHEA version 1 (2012) Rheology analysis software, ABATECH, Philadelphia, USA. http://www.abatech.com/ RHEA.htm

33. Rowe GM, Sharrock M (2011) Alternate shift factor relationship for describing temperature dependency of viscoelastic behavior of asphalt materials. Transp Res Rec 2207(1):125-135

34. Kim YR, Lee H, Little D, Kim YR, Gibson N, King G, Pellinen T, Fee F (2006) A simple testing method to evaluate fatigue fracture and damage performance of asphalt mixtures. In: Asphalt paving technology: association of asphalt paving technologists-proceedings of the technical sessions, vol 75. Association of Asphalt Paving Technologist, pp 755-788

Publisher's Note Springer Nature remains neutral with regard to jurisdictional claims in published maps and institutional affiliations. 